\title{
Black Lives Matter and Catholic Whiteness: A Tale of Two Performances
}

\author{
MICHAEL P. JAYCOX \\ Seattle University
}

\begin{abstract}
The Black Lives Matter movement has received little scholarly attention from Catholic theologians and ethicists, despite the fact that it is the most conspicuous and publicly influential racial justice movement to be found in the US context in decades. The author argues on the basis of recent field research that this movement is most adequately understood from a theological ethics standpoint through a performativity lens, as a form of quasi-liturgical participation that constructs collective identity and sustains collective agency. The author draws upon ethnographic methods in order to demonstrate that the public moral critique of the movement is embedded in four interlocking narratives, and to interrogate the Catholic theological discipline itself as an object of this moral critique in light of its own performative habituation to whiteness.
\end{abstract}

Keywords: Black Lives Matter, racial justice, racism, white supremacy, ethnography, narrative, performativity, whiteness, natural law, virtue

\section{I} $\mathrm{N}$ a bibliographical essay surveying recent scholarship in Catholic ethics, Bryan Massingale addressed the question of whether scholars in this field have succeeded in breaking their near-complete "silence" on the "troubling social evil" of racism. ${ }^{1}$ After offering a cautious expression of hopefulness in response to the literature that has emerged in the past fifteen years, he issued a challenging call for more interdisciplinary research, more engagement with black Protestant scholars, and more warm bodies who are willing to write about racism as a central matter of concern to their discipline. ${ }^{2}$

${ }^{1}$ See Bryan N. Massingale, "Has the Silence Been Broken? Catholic Theological Ethics and Racial Justice," Theological Studies 75, no. 1 (2014): 133-55, at 135.

${ }^{2}$ See Massingale, "Has the Silence Been Broken?," 154-55.

Michael P. Jaycox is Assistant Professor of Christian Ethics at Seattle University and has written on the ethics of anger, social movements, bioethics, ethical method, fundamental moral theology, and Catholic social ethics. His articles have been published in the Journal of the Society of Christian Ethics, Horizons, and Developing World Bioethics. 
Indeed, the fact that only a relatively small number of Catholic ethicists have published any research on the issue reveals the deep structural and ideological complicity of Catholic ethics as an academic community in this pervasive moral evil.

On a general level, the aim of this article is to answer Massingale's call to deepen the "interdisciplinary character" of Catholic ethical reflection on racism by drawing upon performativity literature and critical whiteness studies. ${ }^{3}$ On a more specific level, however, its aim is to remedy the relative lack of sustained scholarly reflection about the Black Lives Matter movement in particular. With the notable exceptions of Shawn Copeland and Vincent Lloyd, both of whom are black scholars, Catholic ethicists and theologians have not published about this movement outside of journalistic sources, blog posts, and casual references. ${ }^{4}$ With the intention to amplify the voices of activists in the movement in order that they may be heard in this emerging scholarly conversation, I traveled to the St. Louis area in summer 2015 to offer my own practical solidarity and witness among the local participants in the movement and to understand the context of their resistance from an academic standpoint by conducting interviews. The present investigation will include some of the qualitative data from this ethnographic research as a way of stimulating and facilitating theological and ethical reflection about the significance of this social movement.

The use of narrative ethnographic methods in the discipline of Catholic ethics is still arguably in a nascent stage of development. When looking at the field of theological and religious ethics more broadly, one can find several examples of this kind of interdisciplinary work that have been published in the last ten years. ${ }^{5}$ The ethnographic work of the activist-

${ }^{3}$ Massingale, "Has the Silence Been Broken?," 154.

${ }^{4}$ See M. Shawn Copeland, "Memory, \#BlackLivesMatter, and Theologians," Political Theology 17, no. 1 (2016): 1-3; and Vincent Lloyd, "For What Are Whites to Hope?," Political Theology 17, no. 2 (2016): 168-81. Although she is a historian rather than a theologian, still see Shannen Dee Williams, "The Global Catholic Church and the Radical Possibilities of \#BlackLivesMatter," Journal of Africana Religions 3, no. 4 (2015): 503-15.

${ }^{5}$ See Todd David Whitmore, "Crossing the Road: The Case for Ethnographic Fieldwork in Christian Ethics," Journal of the Society of Christian Ethics 27, no. 2 (2007): 273-94; the contributors to the volume Ethnography as Christian Theology and Ethics, ed. Christian Scharen and Aana Marie Vigen (New York: Continuum, 2011); Luke Bretherton, Resurrecting Democracy: Faith, Citizenship, and the Politics of a Common Life (New York: Cambridge University Press, 2015); the essays collected under the symposium titled "Ethnography, Anthropology, and Comparative Religious Ethics," Journal of Religious Ethics 38, no. 3 (2010): 395-493; and Leela Prasad, Poetics of Conduct: Oral Narrative and Moral Being in a South Indian Town (New York: Columbia University Press, 2007). Moreover, the increased use of narrative ethnographic methods in theology 
anthropologist David Graeber regarding the Occupy movement, antiglobalization movements, and anarchist movements is well known. ${ }^{6}$ However, given the systemic injustices with which ethicists tend to concern themselves, it would be unethical for ethicists to attempt to use narrative ethnographic methods to "study" a social movement whose members are socially vulnerable or marginal without also inverting the academic gaze to interrogate their own cultures, assumptions, biases, and moral complicity in the very injustices that have occasioned their interest in the research. As Christian Scharen and Aana Marie Vigen have warned, "Complex issues and potential problems arise whenever a white scholar does research that focuses on members of other racial-ethnic groups, including misunderstanding, misappropriation, and disrespect. Moreover, it is possible for the researcher to use whatever s/he learns for her/his own advancement and without sufficient accountability to those who teach her/him with their stories and insights." 7 Getting right to the point, bell hooks argues that there is a fundamental moral problem involved whenever academics attempt to narrate somebody else's suffering:

Often this speech about the "other" annihilates, erases. No need to hear your voice when I can talk about you better than you can speak for yourself. No need to hear your voice. Only tell me about your pain. I want to know

and religious studies runs parallel to a "cultural turn" in social movement theory, which raises a fascinating set of interdisciplinary questions that unfortunately exceed the scope of this project. For a representative sample of the literature regarding the cultural turn in social movement theory, see Myra Marx Ferree and David A. Merrill, "Hot Movements, Cold Cognition: Thinking about Social Movements in Gendered Frames," Contemporary Sociology 29, no. 3 (2000): 454-62; Francesca Polletta, Freedom Is an Endless Meeting: Democracy in American Social Movements (Chicago: University of Chicago Press, 2002); Polletta, "Culture Is Not Just in Your Head," in Rethinking Social Movements: Structure, Meaning, and Emotion, ed. Jeff Goodwin and James Jasper (Lanham, MD: Rowman \& Littlefield, 2003), 97-110; Deborah Gould, Moving Politics: Emotion and ACT UP's Fight against AIDS (Chicago: University of Chicago Press, 2009); Verta Taylor, "Social Movement Participation in the Global Society: Identity, Networks, and Emotions," in The Future of Social Movement Research: Dynamics, Mechanisms, and Processes, ed. Jacqueline van Stekelenburg et al. (Minneapolis: University of Minnesota Press, 2013), 37-57; Natalia Ruiz-Junco, "Feeling Social Movements: Theoretical Contributions to Social Movement Research on Emotions," Sociology Compass 7, no. 1 (2013): 45-54; and James Jasper, The Art of Moral Protest: Culture, Biography, and Creativity in Social Movements (Chicago: University of Chicago Press, 1997).

${ }^{6}$ See David Graeber, Possibilities: Essays on Hierarchy, Rebellion, and Desire (Oakland, CA: AK Press, 2007); and Graeber, Direct Action: An Ethnography (Oakland, CA: AK Press, 2009).

7 Christian Scharen and Aana Marie Vigen, "Preface: Blurring Boundaries," in Scharen and Vigen, Ethnography as Christian Theology and Ethics, xvii-xxviii, at xx. 
your story. And then I will tell it back to you in a new way. Tell it back to you in such a way that it has become mine, my own. Re-writing you I write myself anew. I am still author, authority. I am still colonizer, the speaking subject and you are now at the center of my talk. ${ }^{8}$

From the standpoint of realism, it is probably impossible in practice for academics, particularly those who already occupy a social location associated with significant privilege (in my case, white, male, queer, and middle class), to completely avoid the problem hooks diagnoses, though it is probably possible to mitigate it more or less well.

For the purposes of this project, I will aim to mitigate the problem precisely by avoiding the imposition of my own theological interpretation or ethical judgment upon the narratives that my interviewees agreed to share with me, despite the fact that my own normative biases will inevitably exert some influence. The purpose of using narrative ethnographic methods for this project is not to treat the interviews as "raw material" from which to extract a theology of the Black Lives Matter movement "for" or "on behalf of" the movement's membership. Instead, I will attempt to locate narrative convergences in order to infer an idolatrous "antitheology" of white supremacy exposed by those narratives and to inquire whether and to what extent worship of this idol is performed in Catholic ethics. Thus, the purpose of using ethnography for this project is a political one: to facilitate resistance to white supremacy, to create a space within which members of the Black Lives Matter movement can speak for themselves and be heard by academic theologians trained in Catholic ethics, and ultimately to offer an internal critique of this academic discipline, one in which I necessarily include myself.

Having noted these preliminary points, I will argue that both resistance to and complicity in white supremacy, on the part of the Black Lives Matter movement and on the part of Catholic communities respectively, can be understood as performances. ${ }^{9}$ By this I mean that both groups (membership

${ }^{8}$ bell hooks, "Marginality as Site of Resistance," in Out There: Marginalization and Contemporary Cultures, ed. Russell Ferguson et al. (Cambridge, MA: MIT Press, 1990), $341-43$, at 343 .

9 The category of "performativity" has a broad valence. The varied meanings and usages of the term among academic disciplines are generally understood to have developed from the originating concept of "speech acts" in philosophy of language; see J. L. Austin, How to Do Things with Words, 2nd ed. (Cambridge, MA: Harvard University Press, 1962); and John Searle, Speech Acts: An Essay in the Philosophy of Language (Cambridge: Cambridge University Press, 1969). Judith Butler famously deployed the category as a means of arguing that sex, gender, and even the body itself are socially constructed; see Butler, Gender Trouble, 2nd ed. (New York: Routledge, 1999). Most recently Butler has used the category as a lens through which to understand the political force of multiple bodies occupying public space; see Butler, Notes toward a Performative Theory of 
in each of which overlaps) negotiate their complex locations in the racial hierarchy by inviting their members to participate in ritual or quasi-liturgical activities that enable them to construct and become a narrative-based collective identity, or a "social body." These ritual activities might be disruptive, accommodating, or both with regard to the idol that is our white supremacist system. Thus, it is helpful to interpret many of the ritualized activities of direct action that have been undertaken by the Black Lives Matter movement as symbolic action, in the highest sense of the word. By performing this social body into reality, direct action (as symbolic action) creates optimal cultural conditions for the emergence of the collective narrative and agency needed to sustain the movement's membership. Conversely, it is helpful to consider whether the ritual activities associated with Catholic cultures, whether sacramental participation proper or the institutional culture of academic Catholic theology, perform whiteness and maintain white supremacy. By acting on the basis of their membership in a social body of performed whiteness, Catholics have become deeply implicated in the very moral problems that the members of the movement, thinking and acting as moral subjects and not mere objects of study, aim to address.

In order to unpack this argument and its implications, first I will call attention to two specific instances of direct action undertaken by the local movement in the St. Louis area to aid in an assessment of the performative function of these ritualized activities, and I will describe my own participation in them concurrently with my research activities. Second, I will outline some of the contextual narrative content that the movement has constructed as the collective identity of their own social body, focusing on four specific narrative convergences shared among women (both transgender and cisgender) of color and gender nonconforming persons of color who have participated in direct action and agreed to be interviewed for my research. Third, inverting the academic gaze toward the author and academic audience of this article as objects of critique, I will suggest that the social body of academic Catholic ethicists performs whiteness as our collective identity, in that we are largely complicit in the ritual worship of a white supremacist idol in the broader society to which we also belong. This whiteness undermines our

Assembly (Cambridge, MA: Harvard University Press, 2015). The specific use of performativity in this investigation refers to the gradual creation of collective identity by way of narrative construction and ritualistic participation. For previous uses of performativity in Christian liturgical theology, see Louis-Marie Chauvet, Symbol and Sacrament: A Sacramental Reinterpretation of Christian Existence (Collegeville, MN: Liturgical Press, 1995), esp. 130-35; Aidan Kavanagh, On Liturgical Theology (New York: Pueblo Publishing, 1984), esp. 77-88; and Richard McCall, Do This: Liturgy as Performance (Notre Dame, IN: University of Notre Dame Press, 2007). 
capacities not only to heed the invitation to participate in the Black Lives Matter movement ourselves but also to receive and understand the moral critique of the movement in some of the primary conceptual languages of our discipline, natural law and virtue.

\section{Pink Pigs and Delayed Drivers}

Grassroots movements operating at the edges of civil society in the sphere of participatory democracy, particularly movements organized and led by members of oppressed groups who are not accustomed to the privilege of exercising an openly confrontational voice in political processes, tend to employ "everyday" forms of resistance that undermine and subvert not only the effectiveness of the political structure but also the dominant cultural norms, expectations, and symbols that give legitimacy and authority to that structure. ${ }^{10}$ This has become all the more true in the age of social media and smartphones, as activists in the Occupy, Arab Spring, and Black Lives Matter movements have learned to harness these new technologies as a means of heightening the dramatic confrontation with police and exposing the morally bankrupt dominant culture of their societies. ${ }^{11}$

With regard to Black Lives Matter's own concern to resist white supremacy, Cornel West's words have remained true: “The major enemy of black survival in America has been and is neither oppression nor exploitation but rather the nihilistic threat-that is, loss of hope and absence of meaning. For as long as hope remains and meaning is preserved, the possibility of overcoming oppression stays alive." ${ }^{12}$ Focusing on Black Lives Matter's use of

${ }^{10}$ See James C. Scott, Weapons of the Weak: Everyday Forms of Peasant Resistance (New Haven: Yale University Press, 1985).

${ }^{11}$ See Daniel D. Martin, "The Drama of Dissent: Police, Protesters, and Political Impression Management," in The Drama of Social Life: A Dramaturgical Handbook, ed. Charles Edgley (Burlington, VT: Ashgate, 2013), 157-79; Lauren Langman, "From Virtual Public Spheres to Global Justice: A Critical Theory of Internetworked Social Movements," Sociological Theory 23, no. 1 (2005): 42-74; and Manuel Castells, Networks of Outrage and Hope: Social Movements in the Internet Age (Malden, MA: Polity Press, 2012).

${ }^{12}$ Cornel West, Race Matters, 2nd ed. (New York: Vintage Books, 2001), 23. West has been criticized on this point by the sociologist Eduardo Bonilla-Silva, in Racism without Racists: Color-Blind Racism and the Persistence of Racial Inequality in the United States, 3rd ed. (New York: Rowman \& Littlefield, 2010), 103-4. Bonilla-Silva holds that West's diagnosis of nihilism necessarily implies a conservative, cultural explanation for black poverty, thereby lumping him together with classic articulations of this cultural theory, such as Douglas Massey and Nancy Denton, American Apartheid: Segregation and the Making of the Underclass (Cambridge, MA: Harvard University Press, 1993). 
direct action to construct a world of cultural meaning, rather than on the effectiveness of direct action in producing structural change, yields a more comprehensive understanding because it becomes implausible to dismiss this form of resistance as a peripheral supplement to the "real work" of the movement. Rather, direct action, as symbolic action, is also constitutive of the real work. "Symbolic" is not meant here in the pejorative sense of "merely symbolic," but in the sense of that which has the power to mediate the world that can and should exist, but does not yet exist in its fullness, but which through ritual participation in the action already begins to break into our reality. ${ }^{13}$

Consider, for example, a direct action undertaken by the group Artivists STL. In December 2014, members of this organization made a life-size, papier-mâché pig, painted it pink, and placed a police officer's hat on its head. They named it the "Pignata of Brutality" because, instead of the names of different cuts of pork, they had written inside each of the sections drawn on the pig's body the names of police officers who had killed unarmed persons of color and not been found legally guilty of a crime. The group put a leash around this pig's neck and dragged it along to protests at the police station, at city hall, and at the federal building. After the police officers recovered from their initial shock at seeing the pig, they were actually amused. They knew exactly what it was and exactly what it meant. They even took photographs of themselves with it. The humor had the effect of cutting the tension at the protests, and, for a moment, it allowed the police to see the protesters as human: humans who can laugh, and humans who can bleed when you shoot them. Thus, the symbol had a strange versatility: it simultaneously invited engagement and maintained an oppositional posture. Artivists STL knew full well that this symbol would not change the grand jury's decision not to indict Darren Wilson one month earlier, but it did ground the movement's assertion of the full humanity of black bodies and embolden their intellectual critique of a severely flawed policing and criminal justice system in which officers could effectively be assured of immunity.

As a second example, consider a direct action undertaken by the group Millennial Activists United (MAU) in August 2015, on the one-year anniversary of the killing of Michael Brown Jr. by Darren Wilson. MAU organizers successfully orchestrated a "shutdown" of the westbound and eastbound

${ }^{13}$ See Chauvet, Symbol and Sacrament, 84-109. 
lanes of Interstate 70 just outside of the suburb of St. Charles, Missouri. To execute this action, it was necessary to coordinate ten cars, ten drivers, and a few dozen additional people riding as passengers to the shutdown location, as well as to obtain several large cardboard boxes, which were painted bright yellow and on which was written, "Ferguson is Everywhere." MAU took a deliberately theatrical approach by pretending that these boxes were heavy roadblocks as they took them out of the trunks of the cars and blocked the highway. Shortly after the police arrived, they began to engage in the typical pattern of psychological intimidation, escalation, and physical abuse of protesters, which the activist community has come to expect. During the actual arrests, the police inflicted several injuries on the protestors that required medical attention, a fact that has been extensively documented with photographic evidence posted on social media platforms.

MAU's choice to shut down a highway was not haphazard; it was meant to evoke symbolically the historical and contemporary significance of the highway system as a facilitator of white flight, racial segregation, and economic segregation, all of which have devastated the livelihoods of black families and communities in St. Louis for generations. ${ }^{14}$ The action naturally elicited defensive and vitriolic responses in face-to-face interaction and on social media. "Not being late" was judged by several drivers to be more important than recalling the moral scandal of an extrajudicial killing by the state of a black teenager one year prior.

Like the Pignata of Brutality, the critical point in this case is that none of the MAU organizers or participants supposed that a highway shutdown would actually be effective as a means to the end of structural reforms and disincentives that would make police brutality and extrajudicial killing by the state less frequent. Rather, the purpose of the action was to disrupt the ideological normalcy of black death by creating temporary symbolic conditions that would dramatize the habitual "scotosis" and banality of white supremacist culture. ${ }^{15}$ Moreover, participation in these direct actions

${ }^{14}$ See Colin Gordon, Mapping Decline: St. Louis and the Fate of the American City (Philadelphia: University of Pennsylvania Press, 2008); Clarence Lang, Grassroots at the Gateway: Class Politics and Black Freedom Struggle in St. Louis, 1936-75 (Ann Arbor: University of Michigan Press, 2009); and Richard Rothstein, "The Making of Ferguson: Public Policies at the Root of Its Troubles" (Washington, DC: Economic Policy Institute, 2014), http://www.epi.org/files/2014/making-of-ferguson-final.pdf.

15 See M. Shawn Copeland, Enfleshing Freedom: Body, Race, and Being (Minneapolis: Fortress Press, 2009), 13-15, where she uses the Lonerganian epistemological categories of "scotosis" and "bias" to interpret the pattern by which whiteness attempts to maintain the intellectual plausibility of racial hierarchy by habitually distorting, overlooking, avoiding, and denying evidence to the contrary. 
functions performatively, in that group resistance creates the social conditions for constructing the narrative-based collective identity, or social body, of the movement.

When I arrived in St. Louis in the summer of 2015 to do my research, I was an outsider to the movement itself, having been involved only in a very peripheral and noncommittal way beforehand. I had only three things to bolster my credibility in the eyes of the local movement: a few contacts with local clergy and academics; the fact that I belong to the LGBTQ community (many of the local organizers do as well); and my temporary position as scholar-in-residence at the Center for Social Empowerment in Ferguson, where I had an office. Everything else about me, including my being a white-categorized body, my being a cisgender male, my academic credentials, and my outsider status, were liabilities for building relationships of trust with the local movement, who had every reason to be suspicious of my motives. Thus, it is well worth asking whether I had any right to be there in the first place, and how I was eventually able to persuade strangers to sign an informed consent form and participate in an audio-recorded interview. Although I have no good answer to the first question, in regard to the second I am convinced that it was my own ritual participation in direct action that eventually incorporated me into the social body of the local movement. Willingness to take risks, as a part of the movement rather than an outside observer of it, was integral to the cultivation of trust. Doing so had the effect, almost in passing, of breaking down the colonialist framework of researcher "subject" and researched population "object" within which I had been operating despite my own awareness of it as a problem and my own best individual efforts to dispel it.

After the local movement organizers learned that they couldn't get rid of me, but also that I was willing to do risky work, they started putting me to work by inviting me to take some actual risks. For example, while volunteering as a legal observer for a direct action at the courthouse in downtown St. Louis on Moral Monday in August, I crossed some "do not cross" barriers to get photographic evidence of police activities. I helped paint the boxes and drove one of the cars during MAU's highway shutdown later the same day. After St. Louis County police decided to hold the MAU organizers as political prisoners in retaliation, I was among those who blocked the police station entrance in order to demand their release. All of these actions took advance planning, coordination, and real trust built really quickly. Afterward, the other members of the movement unsurprisingly started being more willing to speak with me. We were no longer subject and object; we were all subjects differently engaged in the same struggle, constructing the narratives of the movement and our own identities together. 


\section{Four Narratives, One Social Body}

In order to contextualize these narratives, it is necessary to note the social locations of the members of the movement. Although it is difficult to determine who would and would not "count" as a member, I decided that those who participate in direct actions or who provide support structures for those who participate would count as members of the movement for the purposes of the research. If this is the criterion, then the movement is quite internally diverse from a demographic standpoint, in terms of not only race but also gender and age. When considering potential candidates for interviews, I aimed to represent the membership of the movement in a way that was proportional to the demographic distributions I was able to observe. Based on the demographic data I collected prior to conducting each of the 21 interviews involving 23 interviewees, they self-identified as mostly female, transgender, or gender nonconforming (accounting for 69 percent of the total), mostly persons of color (accounting for 56 percent), and mostly younger than 40 (accounting for 69 percent). ${ }^{16}$

As previously mentioned, I will prioritize methodologically the convergences among the narratives being constructed by women (both transgender and cisgender) and gender nonconforming persons of color. ${ }^{17}$ It would be very easy and tempting, as a reflection of the current power structure and reigning ideologies, for academics to give first consideration to the narratives being constructed by white persons and cisgender males. While it is true that ethical thought and agency are inescapably situated in particular narratives

${ }^{16}$ Parenthetically it is worth noting that my own race, gender, sexuality, economic class, and education level as the researcher did affect which persons were and were not within my "network" of prospective participants, both for the better and for the worse. The current wisdom in ethnographic methods holds that when researchers and participants do not belong to the same race, the actual data collected ends up being different from, but not necessarily worse or better than, when researchers and participants do belong to the same race; see France Winddance Twine, "Racial Ideologies and Racial Methodologies," in Racing Research, Researching Race: Methodological Dilemmas in Critical Race Studies, ed. France Winddance Twine and Jonathan W. Warren (New York: New York University Press, 2000), 1-34, at 13; and Penny Rhodes, "Raceof-Interviewer Effects: A Brief Comment," Sociology: The Journal of the British Sociological Association 28, no. 2 (1994): 547-58, at 552.

17 This work of articulating the narrative convergences does of course require interpretation on my part, though I have tried to preserve the intentionality of the interviewees as best as possible. For more information on narrative convergence as an ethnographic method for interpreting qualitative data, see Jaber Gubrium and James Holstein, Analyzing Narrative Reality (Thousand Oaks, CA: Sage, 2009). 
and thus in the specific communities who have constructed them, ${ }^{18}$ a consideration of the actual power relationships that maintain systemic injustice suggests that narratives being constructed by oppressed groups are the product of an epistemologically privileged perspective and, as such, constitute a moral critique of hegemonic narratives that function to protect privilege. ${ }^{19}$ It is therefore necessary for the relatively privileged author and audience of this article to employ a series of methodological "replacements" for the purpose of interpreting these narratives: to replace a default liberal hermeneutic of tolerance with a more radical hermeneutic of prioritization, to replace an aspiration to diversity with the challenge of solidarity, to replace the powerconcealing dynamics of inclusivity with a deliberate decentering of dominant voices, and to replace the measure of equality with the measure of equity. ${ }^{20}$

That being said, it is possible to identify four major points of narrative convergence among the women and gender nonconforming persons of color whom I interviewed: fatigue, dehumanization, myth debunking, and delayed liberation. To illustrate each of these points, I will offer short excerpts from the interviews, accompanied by necessary contextualization, the aliases chosen by the participants, and demographic information in parentheses.

\section{Fatigue}

On a Wednesday evening in August 2015, only one month after the death of Sandra Bland, I met Yvonne (black, female, age 30-39) at a small direct action in Ferguson. Afterward we exchanged phone numbers to stay in contact, making it possible for us to meet again the following Saturday afternoon in a coffee shop in St. Louis. There I also met her friend Alice (black, female, age 30-39), and the three of us decided to go to Yvonne's home for the interview. Toward the end of our conversation, which lasted almost two hours, Yvonne told me a story about two friends, both white men, who had been "marked" as "race traitors" by the city police for

${ }^{18}$ See Alasdair MacIntyre, After Virtue: A Study in Moral Theory, 3rd ed. (Notre Dame, IN: University of Notre Dame Press, 2007); and Stanley Hauerwas, A Community of Character: Toward a Constructive Christian Social Ethic (Notre Dame, IN: University of Notre Dame Press, 1981).

19 Susan Moller Okin's scathing critique of MacIntyre is apt here, in that the ultimate justification for his narrative-based ethics is an appeal to "classical" traditions and virtues instantiated in local cultural contexts, a system that she argues is incapable of addressing the problem of social domination as injustice; see Okin, Justice, Gender, and the Family (New York: Basic Books, 1989), 42-62.

${ }^{20}$ See Roberto Goizueta, Caminemos con Jesús: Toward a Hispanic/Latino Theology of Accompaniment (Maryknoll, NY: Orbis Books, 1995), 177-82. 
protesting the nonindictment of Darren Wilson. As the two men were walking home, the police followed and threw a tear gas canister at them "just for fun."

Yvonne: Yeah, and he said to me, you know, "I've been woke," in so many words. He said, "I've been in this movement from the start," but it was at that moment that he got angry. And he'd been hurt, he'd been in pain, he'd been empathetic, but when that happened to him, he got mad. And, um, the fatigue ...

Alice, interrupting: It's worse if you're darker.

Yvonne: Yeah.

Alice: It's worse if you're darker. And I'm at fatigue stage. I mean, I have to do the whole self-care thing. I have a life that I'm fighting for. There's things that I care about doing in tandem to this movement, and my work in the movement isn't gonna mean much if I don't do the thing that I care about. And it's a multitasking game. And I have to take care of that before I can do the movement. And I know that other people are stronger than me, not as triggered as I am, to keep it moving. But, I got a lot of-being that introvert-maybe it's not me being introverted. It's me being traumatized. I'm not sure which it is. But I gotta pull away, recharge, get my shit together, step back and relate to people again, but, yeah.

In the course of Yvonne's story about the targeting of the two men, Alice redirected our conversation toward a much deeper narrative. The activity of merely listening to somebody else's encounter with police violence was enough to prompt Alice to return to her own experience of traumatization. The "fatigue stage" she described, characterized by frequent triggering that reawakens the traumatic memory of past violence and the need to engage in self-care, is a deep narrative shared among many women and gender nonconforming persons of color who are involved in the movement.

Carmen (black, female, age 18-29), whom I met in Ferguson at a church gym that was functioning as a supply center for the movement, identified a collective experience of "fatigue here in the activist community," and she linked it explicitly to the intimidation tactics and outright violence routinely employed by the police. Likewise Jamie (black, gender nonconforming, age 18-29), whom I interviewed the day after an impromptu street gathering in response to the city police's having killed Mansur Ball-Bey, spoke with me in a coffee shop about the psychological effects of having repeated standoffs in the street with police:

Jamie: We'll get tired of continuing to do what we do and, like, having the same, like, "I'm gonna go scream that my life matters in the streets 
and then get arrested and tear gassed during that." Um, like, people get tired of that. So I think that things might have to go different. I don't know.

Michael: We were talking about fatigue earlier, and how a lot of people in the community have been experiencing that, right?

Jamie: Mm-hm. [Long pause]

Michael: Today's a day.

Jamie: Today is a day. Today I was like, "I was gonna ... [pause] come," I didn't really want to come, but I knew I had to meet with you, so like, I might as well just come here, because I wanted to be a recluse and not talk to anybody and, like, try not to be on social media, 'cause I knew that was just gonna piss me off.

The fact that women and gender nonconforming persons of color consistently reported this fatigue as a way of framing their experience in the movement is probably sufficient grounds for treating it as a major point of narrative convergence. It is all the more notable, then, that this narrative was not as consistently invoked by the men of color, the white women, or the white men whom I interviewed.

For example, Tim (black, male, age 30-39), whom I met a few hours before the direct action at the courthouse in downtown St. Louis on Moral Monday in August, identified himself with Brown, saying, "That could have easily been me at that age." After noting that Wilson had a reputation for repeated harassment of young black men in the Canfield neighborhood, Tim continued to empathize with Brown:

Tim: St. Louis in August is usually hot. And so you're hot, you're angry, you're thinking about you know what he's done before, and sometimes you're just not going to take it. Like, [pause] can I curse on this?

Michael: Yeah.

Tim: Yeah, it's like, you know, " $\mathrm{F}^{* *} \mathrm{k}$ this, I'm gonna say something today." And so I completely understand where, like, his mind was at that day.

Tim did not frame his emotional response to repeated police harassment and violence in terms of fatigue, as Alice, Carmen, and Jamie did. Rather, Tim spoke of openly expressed anger. Rebecca (white, female, age 18-29), whom I met at the Ferguson public library, reported feeling anger as well as helplessness, defeat, and "utter terror" in response to the police's violent treatment and political imprisonment of the MAU organizers in retaliation for the Interstate 70 shutdown. Charles (white, male, age 60-69), whom I met 
through some of my initial contacts with clergy in the area, emphatically and repeatedly expressed his anger about the "aggressive response" of the police toward the protests in Ferguson, particularly in regard to the way it was affecting the developing psyches of small children in the area, but he gave no indication that he felt fatigued by the experience.

Therefore, while the fatigue narrative is indeed a point of narrative convergence in the movement, this is also a gendered and raced way of conceptualizing one's experience, in the sense that one is trying to sustain resistance from the intersectional social location of being both a female or gender nonconforming body and a black or brown body. The reality of unjust social hierarchies prevents bodies in this social location from expressing anger exclusively in the mode of open aggression, particularly in relation to white and male opposition. The social and psychological risks of doing so over an extended period of time are simply too high. Indeed, in some cases, the system prevents bodies in this position from even allowing themselves to become fully cognizant of their own anger.

For instance, Yvonne and Alice were most willing to attribute anger and rage to police officers, emotions that for them consistently held a negative connotation, while they described their own attitudes toward the policing system as "tiredness," "frustration," "fed-up-ness," and on a few occasions "infuriated," all of which they considered to be positive catalysts for social change. Toni (biracial, female, age 30-39), whom I met through my legal observer activities, explicitly claimed that the "people first got out in the streets" in Ferguson because of "a group of young men that were angry and hurt." Sofia (Latina, female, age 40-49), to whom I was introduced in a coffee shop by one of the activists who was arrested during MAU's highway shutdown, suggested that the default "aggressive posture" activists assume during "the cop-line standoff" is a learned behavior that mirrors the police's own stereotypically masculine way of engaging conflict. This social norm works to center men's experiences and marginalize women's experiences of participating in the movement. Sofia said this even while acknowledging and expressing her own anger in a very animated manner during our interview.

Therefore, on the basis of these interviews, we can infer a generalization about participation in the movement: the closer your social location is to being a black or brown body and female or gender nonconforming body, the more likely you are to resonate with a fatigue narrative rather than an anger/aggression narrative. For those who resonate primarily with a fatigue narrative, there is a necessity to experience and express the anger you do direct toward the system in a simmering way, in a cold way, in a more subtle way, for the sake of self-preservation and for the sake of sustaining an appropriately oppositional stance toward that system. 


\section{Dehumanization}

In our interview Toni told me multiple stories, many involving members of her own family, to illustrate a pattern of police intimidation and violence toward black and brown bodies in Ferguson, based on the presumed criminality of those bodies. She offered a helpful analogy that cut directly to the heart of the matter:

Toni: This whole situation, it leaves the black community very vulnerable, and especially with white supremacy teaching us that we are responsible for every bad thing that happens. We're responsible for every thief, everybody. We're supposed to be embarrassed, we're supposed to be ashamed, we're supposed to stop the bad apples. And regardless of my degrees, or who I am, or what I've done, I can't expect to walk into a store and not get followed, because another black person might come in and steal. And, again, that's ridiculous, because people within the white community-and we don't even say "white community," and there's a reason for that, because the "white community" gets the privilege of having individual identity.

Michael: Right, right, right. Instead of having, being, like, sort of, how do I put it?

Toni: Okay, so I'm a big Star Trek fan, and I know unfortunately nobody watches Next Generation, but I always liken it to-have you ever watched it?

Michael: Oh, I've seen Next Generation. Yeah.

Toni: Okay, good! I've always likened it to-they view black people as the Borg. Like, the Borg Collective. We are one. We feel everything that one feels, we adapt, we basically are one. We move as one. And no individuality, unless somebody makes it out of the horrible situation, and all of a sudden that person is an exception, and then we will pull him away or pull her away from the Borg collective and use that person to say, "Why can't the rest of you do it?" [Laughs] So, yeah. [Pause] The biggest issue is not only society, but the police who come from the society, that they treat black people as all one-we are all responsible for the lowest of the low-while granting white people individuality. They use it as an excuse to "other-ize" us, to dehumanize us.

Toni frames the systemic pattern of discriminatory policing toward black and brown communities in terms of a more fundamental narrative of dehumanization, as a gradual "stripping away of humanity," to use her own phrase. Furthermore, she noted that the presumption of black and brown criminality, a major aspect of having this dehumanized status, is 
often internalized psychologically by the members of black and brown communities as a result of their being socialized into a dominant culture of white supremacy. ${ }^{21}$

In a similar vein, Renee (black, female, age 50-59), whom I met at a community meeting about policing reform in Ferguson, drew upon her decades of experience living in the area when she noted that black bodies are simply "not given the benefit of the doubt" by the local police, essentially being rendered guilty until proven innocent. Similarly, Jackson (black, male, age 40-49), whom I met at a block party in St. Louis during the events of the anniversary weekend, commented on the work of the younger members of the movement in a way that demonstrates the centrality of the dehumanization narrative: "Yes, of course they want better policing of black bodies, more fair and equitable policing of black bodies, and safer policing of black bodies. Of course they want that, but what they're really fighting is a culture of neglect, a culture of almost normalized superiority for certain groups and normalized inferiority for other groups." Also reflecting on the problem of normalized black dehumanization, Tim posed the critical question: "How do you get out of a mentality where black people are the target all the time?"

Yvonne and Alice agreed that the cultural pattern of attributing "collective guilt" for violent crime to all members of the black community is a dehumanizing "nod to white supremacy," and they used specific examples of their being arrested after participating in direct actions to illustrate the point. However, they also spoke at length about their experiences of being dehumanized by everyday encounters, by the sheer accumulation of microaggressions, a "subversive" pattern of speech operating "underneath the surface" of their conversations with white people. After expressing their exasperation about being dehumanized by the microaggressive speech, premature intimacy, and tokenization coming from their white acquaintances and even white allies in the movement, they concluded that white people are motivated to engage in these types of behavior because they are "burdened" by white guilt, yet paradoxically still desire to maintain their position of racial dominance. Using explicitly religious language, Yvonne said, "They actually want us to absolve them of their sin." As an alternative to absolution, Alice made a simple request: "I want these people to see me as a human, not just the representative of black people or the one that isn't like the other black people."

This dehumanization narrative can be understood in sociological terms as an indication that white supremacist ideology is providing legitimation for a

${ }^{21}$ This narrative closely resembles the work of Khalil Gibran Muhammad; see Muhammad, The Condemnation of Blackness: Race, Crime, and the Making of Modern Urban America (Cambridge, MA: Harvard University Press, 2010). 
structure of discriminatory policing that simply presumes the legal guilt of all black and brown bodies ahead of time, quite aside from the eventual result of a criminal investigation or trial and without regard for basic human rights. Accordingly, much of the actual organizing work of the movement in the St. Louis area is focused on addressing this structural problem, whether by collecting the evidence needed to take legal action or by reforming local police departments toward a more broadly accountable community policing model, as recommended in the US Department of Justice investigation of the Ferguson police department. ${ }^{22}$ However, the dehumanization narrative testifies to a reality of which the members of the movement are also keenly aware, namely, the pervasiveness of the much deeper cultural problem of white supremacist ideology, which is comparatively much more difficult to "reform" from an ethical, legal, or political standpoint.

\section{Myth Debunking}

Expanding upon his previous remarks about the culture of "normalized inferiority" of black bodies, Jackson provided several familiar examples of how this dehumanizing ideology is already reflected in the social structure, such as racial inequities in the public school system, in access to grocery stores, and in the criminal justice system. The job of the movement is essentially to disrupt this normalization of black inferiority:

Jackson: It took these young people to kind of jolt us out of that and to see that this is not normal, this is dysfunctional! And so, I think that's the beauty of this particular movement. I'm enjoying being jolted out of whatever sense of normalcy has pervaded my feeble mind, and that's important.... Now mainstream America cannot deny this, and in many ways you can't deny what you're seeing on the video, and you will try, you will try. [Laughs] But the truth is at that point, young people had won. The young people had won because they had pulled the curtain back.

In a way, Jackson is granting a certain amount of epistemological privilege to the movement itself, a capacity for critical moral perception based in an embodied, collective refusal to pretend that the dominant explanations for racial inequity are plausible. When the members of the movement exhort

${ }^{22}$ See United States Department of Justice, Civil Rights Division, "Investigation of the Ferguson Police Department," March 4, 2015, https://www.justice.gov/sites/default/ files/opa/press-releases/attachments/2015/o3/04/ferguson_police_department_report. pdf. 
one another to "get woke" and "stay woke," they are practicing group intellectual resistance while simultaneously recognizing the difficulty in sustaining critical consciousness against the creeping myopia into which the power of white supremacy would lure you. Meanwhile, for those actively opposed to the movement who are thoroughly invested in upholding white supremacy, a different kind of resistance is happening: all available energy will be spent on trying to deny the plain truth of what is seen and heard. As Renee put it so pithily, "If you in it, you probably can't see it."

For example, shortly after the August 19 incident in which militarized police responded to residents with questions about Ball-Bey by releasing tear gas into the neighborhood, I shared an evening conversation with two undergraduate students in the St. Louis area who had been active in the movement from the beginning of the Ferguson uprising, Assata (black, female, age 18-29) and Malcolm (black, male, age 18-29). Malcolm expressed his frustration about watching the same pattern unfold that he and Assata had seen one year prior in Ferguson:

Malcolm: It just insults your intelligence. Nobody can get a name of the officer involved, but everybody wants to know, everybody knows the name of the victims. It's too many unanswered questions. And rather than try to cover the civilian perspective-the ones who aren't employees of the state-we get given their [the police's] perspective first, which is not always the best thing when you're trying to give a fair and balanced view of the story. So, I mean, people read that and they take it as it is. I think people like to believe in the people who have been their "protectors," or whatever. They want to believe in this comfortable idea that they're in a space where things are equal, where things are fair. Nobody wants to think there's still more work to be done in making things more equitable and fair, stuff like that. And so, whenever somebody says that the people who are in charge of keeping things fair aren't being fair, it's like, "What are you talking about?" And, unfortunately, that's what this movement's about. It's uncovering, it's debunking those myths.

Assata continued this line of thought, explaining what this myth debunking $^{23}$ involves in practice:

${ }^{23}$ Please note that the term "myth" is not meant in the literary sense of a symbolically dense narrative that helps the members of a culture remember who they are (a sense such as you might expect), but instead in the more pejorative, colloquial sense of a false belief that is widely held to be true. 
Assata: I think that some people are being woken up, or have been woken up. I think that part of what people thinks it takes is part of why people are protesting-like, "You're too unbothered. This isn't affecting you. This isn't bothering you. So, let me come to you, and bother the hell out of you, and tell you what's going on! And you're gonna hear me whether or not you want to."

Regardless of whether the members of the movement are successful in persuading those merely not participating the movement or those actively opposed to the movement, it remains the case that the social context of the movement itself can serve as a community of intellectual resistance to the socially dominant white supremacist metanarrative. Several other interviewees illustrated Malcolm's and Assata's generalizations as they expressed critical views grounded in specific experiences of group resistance. For example, Carmen noted that she witnessed camerapersons lowering and turning off their cameras right before the police would use pepper spray on activists in Ferguson. She knew that the police often behave illegally, but social elites had already enlisted the mainstream media to protect society from that knowledge. Toni noted that the internalized "voice of white supremacy" encouraged black residents to view Ball-Bey as a "thug" whose death did not deserve attention by comparison with the contemporaneous fatal shooting of Jamyla Bolden, a nine-year-old black girl. Toni knew that all black lives have intrinsic value that can't be earned, but many within her own community were nevertheless convinced that the conditional value of their lives needed to be continuously earned.

Tim compared his own experiences of the police in St. Louis to those relayed to him by his father, who was involved in the civil rights struggle in North Carolina, and as a result he came to a conclusion that is becoming widespread in the movement:

Tim: I just feel like the police haven't changed ever, that they've always had the same purpose, which is to protect rich people and their property. And I feel like "race relations"-if you can even call it that, I don't, we're all one race-like, have changed since then, but the police haven't. And I don't think the police have changed since slavery because, I mean, they were first really out to be slave catchers.

Tim debunked the myth that the institutional design and purpose of the contemporary policing system is "to serve and protect" by calling attention to the purpose and function of its historical precursor systems: to protect the economic and political interests of the elite class (including white enslaver bodies), most notably the defense of their legal right to private property 
(including enslaved black bodies). ${ }^{24}$ Yvonne and Alice similarly performed their identities as myth debunkers with reference to the category of race itself, moving our conversation in a poetic direction:

Yvonne: We have a good friend who's an author. She came through last year, right when everything started. She came through this year for the anniversary. And she said the lies, the core lie that not just people of color but even white folks have decided to believe, that you made the choice to believe, the core lie is that people are not equal, that some were created to have power and dominion, and some were created to be subservient.

Alice: Yeah.

Yvonne: It's a core lie!

Alice: It is, sister.

Yvonne: It is age old.... Deep down, somewhere, we've all believed the lie that there's some human, somewhere, or there's some group of humans somewhere, that was not made as good or as well as we were. For African Americans, that's all kinds of people. And for white folks, that's all kinds of people. But the truth is, until we can all free ourselves, until we are all liberated from the oppression of, even the presumption of race, which is part of the core lie, multiple racesit's a lie! But we're so covered in it, we're so buried in it, that even black folks in America can be complicit in their own oppression.

By describing the myth of essentialized racial difference as a "core lie," Yvonne and Alice were not merely saying that race is a socially constructed

${ }^{24}$ The scholarship on this topic is large and interdisciplinary. For a representative sample, see W. E. B. Du Bois, Dusk of Dawn: An Essay toward an Autobiography of a Race Concept (New York: Harcourt, Brace \& World, 1940), 182-83; Du Bois, The Souls of Black Folk, ed. Henry Louis Gates (New York: Oxford University Press, 2007), 84; Gunnar Myrdal, An American Dilemma: The Negro Problem and Modern Democracy, 2nd ed. (New York: Harper \& Row, 1962), 525-26, 530-34, 538-43; Samuel Walker, Popular Justice: A History of American Criminal Justice (New York: Oxford University Press, 1980), 55-65, 117-23; Philip Reichel, "Southern Slave Patrols as a Transitional Police Type," American Journal of Police 7, no. 2 (1988): 51-77; Hubert Williams and Patrick Murphy, "The Evolving Strategy of Police: A Minority View," Perspectives on Policing 13 (Washington, DC: U.S. Department of Justice, 1990), 1-15, https://www.ncjrs.gov/pdffiles1/Digitization/ 121019NCJRS.pdf; R. I. Mawby, "Variations on a Theme: The Development of Professional Police in the British Isles and North America," in Policing across the World: Issues for the Twenty-first Century, ed. R. I. Mawby (London: UCL Press, 1999), 28-58, at 31-32; and Sandra Bass, "Policing Space, Policing Race: Social Control Imperatives and Police Discretionary Decisions," Social Justice 28, no. 1 (2001): 156-76. 
category. They attributed to the dominant white supremacist metanarrative an almost spiritual power over human society. To resist it by naming it as a "core lie" is to resist evil embedded in the social and intellectual structures of the world.

Given the sheer number of my interviewees who expressed some version of this critical stance toward the dominant white supremacist metanarrative, the task of debunking myths is not merely something the movement does; it is something that enters into the very identity of the members of the movement. This is no mere academic exercise in ideology critique; this is the performed identity of a resistance movement. Sofia encapsulated this social reality perfectly by saying, "If we can educate ourselves, deconstruct all the myths that we believe about ourselves and our country," this can be a way "to deepen the movement within ourselves."

\section{Delayed Liberation}

At a certain point in my conversation with Yvonne and Alice, I asked them whether they think it would be a good idea for prominent figures in the local movement to run for elected office. They responded with ambivalence and realism, noting the possibilities but also the limitations involved in trying to attain black liberation by means of the established, largely corrupt, local political process in the St. Louis area. They then explained their meaning by appealing to a deeper narrative:

Yvonne: We are poor, you know? We are broke. And that's, to me, why the theology of suffering is so important for us to understand.... Because we probably will never, ever experience the opportunity to have dominion in this land the way that we really wanted to. We're gonna be fighting our whole lives. We're gonna be fighting and struggling and suffering our whole lives.

Alice: I think another 200 years of this is gonna be going down, if they keep the fight going, you know.

Michael: It sounds like this is gonna be a long haul.

Yvonne: Absolutely.

Alice: We'll be dead by the time we get-our people get what they need, before the Native Americans get what they need, before the Mexican immigrants get what they need, before black people get what they need.

Yvonne: Yeah, it's so true.

Alice: It's gonna be years and years-I think at least two centuriesbut we'll be dead and gone, and the work will still continue. 
Yvonne: Yes. It's so true. That's so true.

Michael: So, it seems like you're optimistic about the possibility that eventually the movement will attain its goals, but you just are realistic also about how long it's gonna take. Am I hearing you right?

Alice: Yes.

Yvonne: Absolutely. I mean, I'm not giving up hope. Folks used to say, [singing with Alice] "I don't feel no ways tired." [speaking alone] Um, actually, the people that wrote that song were born and bred St. Louisians, the O'Neal Twins.

Yvonne and Alice, singing: "I've come too far from where I started from, and nobody told me the road would be easy, and I don't believe he brought me this far to leave me." [Laugh together]

Yvonne: That's such a good song! Oh!

By framing their immediate experience within a broader narrative of extended struggle against white supremacy throughout history, Yvonne and Alice were able to sustain their participation in the movement. Moreover, they referred to themselves by using the explicitly religious language of the "remnant community," indicating their realism about how long the struggle is likely to be and how few persons of color are actually going to be interested in participating. At the same time, they didn't romanticize this struggle or take themselves too seriously. After singing the song, they playfully and affectionately imitated the stereotypical "church mothers" who would respond to inquiries about their health by reciting the Langston Hughes poem "Mother to Son" and singing the same song. Humor, suffering, faith, realism, and perseverance are all bound together in this liberation narrative.

Assata and Malcolm offered a somewhat different version of this same narrative when I asked them a question:

Michael: So, a chant that I often hear at events is, "We will win. We are going to win."

Malcolm: Yeah.

Michael: Is that true? Do you believe that the movement can win?

Assata: I mean, I look at it as, "We will win or we will die." The idea behind it is that we're not gonna stop until we have won. If we haven't won, we're gonna be dead. Hopefully by then, you know, there's already some babies born in the revolution, and hopefully it'll be the next generation's job and idea, the same thing, like, "We're gonna win, or we're gonna die." And I think already we've seen some steps towards it. Very small in the grand scheme of things, but steps towards it. A lot of people are starting to connect the dots of like, "I 
remember when Ferguson happened," and I remember being surprised, like, "Wow, this happened," and I was tweeting about it, and people in Palestine were responding to my tweets like, "Hey, this is what you do." So, for me, I'm learning how interconnected things these days are, which I think is a step towards getting that liberation that we talk about, 'cause I don't know if we will win in this lifetime. I don't know if I will get to see it, but I know that I will die chasing the wind, you know?

A few minutes later, when the conversation moved toward the sources from which we get our hope, Assata picked up her previous train of thought again:

Assata: I believe in an idea of what I think people are in their core. Michael: What's that?

Assata: Ah, it's kind of tied to, I guess, spirituality or religion, you know? I believe we all have a creator, and we all come from the same creator, and we're all born into this world with a core, with core themes, like, we're born honest. We're born true. We're born observing. We're born learning. We're born open. We're born flexible. You know? We're born like, kinda to learn and to love! [Laughs] And I feel like my hope comes from people before me, from ancestors, from knowing what they've been through to where we're at now. If I ever get discouraged, I remind myself, like, "Hey, you know, 300 years ago, you was probably somewhere in a cotton field," you know! [Laughs] "So, you've made a lot of progress." And they didn't lose hope, and they'd been slaves for hundreds of years, and it continued and it went on. So I feel like it's my duty, being the offspring of that and coming from that, that I have to have that same hope and that same push so that 300 years from now, my great-great-great-great-greatgrandkids are having this conversation, and they can say, "Hey," you know, "Our grandmother, she never would have thought of the things we're doing now and dealing with now." I think we have a job to the creator and to our ancestors to keep pushing and keep hope alive, because if the hope-usually, if the hope dies for a generation, the next generation doesn't get it. And then what happens is improvements aren't made, people become complacent, and this oppressive system wins. And, for me, that's not an alternative I'm okay with. So, if the alternative to this oppressive system winning is me keeping hope and continuing to fight, then that's really the only route that I see. 
When Assata's narrative is compared with the narrative articulated by Yvonne and Alice, a point of convergence emerges. Black liberation is certain to become a reality in human history, but it is also certain to be so delayed in coming that the current participants in the movement are fully aware of the low likelihood that they will attain the goal in their lifetimes. In fact, Malcolm suggested at an early point in our conversation that what we now know as the Black Lives Matter movement is just the current phase of a popular movement of resistance against white supremacy about 500 years in the making.

Toni's narrative of liberation exhibited similar themes, but she chose to focus explicitly on how the distinctive features of the local struggle in the St. Louis area shape the culture of the movement there. After recalling the fact that Bob McCullough, a major opponent of the local movement who presided over the grand jury that elected not to indict Darren Wilson, has been the prosecutor for St. Louis County for almost twenty-five years, she remarked on the intransigence of the local political establishment:

Toni: See, that's the thing with St. Louis, it's very corrupt. It's a very different animal from other cities, so we have a little bit of work to do. And I guess it's good that the movement was birthed-well, whatever-sparked, erupted-the heart is in St. Louis. Since we are sowe're almost behind Mississippi and Alabama and the rest of the South, it's almost a good thing, because that means that we'll still be here working to change until everybody, everybody all over the country gets free.

Michael: Right. "I'm not free unless everyone's free," sort of.

Toni: Exactly. And we have a lot of, you know, wonderful activists who are on fire and are not gonna give up. And so, I guess, you know, it's kind of a good thing St. Louis is hurting it-it's hurting white supremacy by being so stubborn! Because, if it would just, if it would just stop, we might be quiet, and we might go away, and the rest of the nation would stop making changes. So, even though it's tiring and sometimes disheartening, just talking to you made me realize that, you know, we're in the heart of America, and the heart of America really is quite racist. And so, I guess it's a good thing that we'll still be here while the rest of the nation is seeing change. We'll be here until the end, and eventually St. Louis is going to have to change.

Toni specifically highlighted the fact that struggling against white supremacy, especially in the St. Louis political context, has a considerable cost for the 
members of the movement over time. They will be the last part of the larger movement to experience the fruits of racial justice having been attained, despite the considerable effort they are expending in the meantime with few tangible results. Twice Toni said, with not a little awareness of the paradox, that this is a "good thing."

Assata similarly emphasized that the long-term cost of participation in this struggle is often, or even usually, the loss of a "respectable" reputation, income, psychological and physiological health, or even one's own life. Despite this considerable level of risk, Yvonne, Alice, and Jamie remain undeterred from participating, all of them noting that they draw sustenance from an irreducibly spiritual aspect to the movement. In Jamie's words, "Love for black life is why I continue, and love is spiritual. That's why a lot of-I mean, that's why we all are doing this, 'cause people are dying, and it's our people, and we love them."

While it remains true that the movement is quite internally diverse in terms of what kind of liberation is to be expected and hoped for, there was agreement among not only Toni, Assata, Yvonne, and Alice but also Malcolm, Carmen, Renee, Jackson, Sofia, Rebecca, Jamie, and Tim about one simple truth: no institution has ever granted any oppressed group the rights they deserved without that group "agitating," "bothering," "interrupting," and "putting pressure on" that institution through direct action that gradually erodes the cultural perception of that institution's legitimacy. To suppose otherwise, that social change comes only through "top-down" changes in legislation and policy initiated by the institutions themselves, would be, in the words of Jackson, "a myopic view of things. That's ahistorical." Thus, whether the different members of the social body of the movement adopt an identity based on the tactics of "We shut shit down" (which was more common among members younger than 40) or the tactics of "We change the hearts and minds of our oppressors" (which was more common among members older than 40), the conceptual understanding of the purpose of direct action in service to a very long struggle of liberation is essentially the same in both cases.

The members of the movement have learned that white supremacy has sufficiently corrupted the major institutional structures of society (e.g., the market economy, democratic representation in government, the criminal justice system, the education system) that "the whole damn system is guilty as hell," to invoke the protest chant. Thus, conventional forms of participation in these structures in order to reform them have become increasingly less viable. The membership has responded to this reality by becoming a new social body, continuously employing symbolic cultural subversion and narrative construction to create alternative modes of belonging and participation 
that can support and sustain participatory democracy in service to black liberation over an extended period of time. This is, in essence, the performative function of the work of the Black Lives Matter movement.

\section{Catholic Ethics and the Elusive Problem of Whiteness}

How do the voices and actions of the members of the movement speak to us in the Catholic theological academy? More to the point, how do we know whether we have appropriately received this social body as a disruption of our own? It is impossible to answer these questions without assuming that the author and audience of this article also inhabit a performative identity requiring continuous ritual participation and narrative construction to sustain it. We must invert the academic gaze toward ourselves by asking about our own complicity in white supremacy. ${ }^{25}$ In other words, we are invited to receive the direct actions and narratives of the Black Lives Matter movement as an indictment and moral challenge posed to US Catholics in general and Catholic scholars in particular, specifically in our capacity to be participants in the ritual worship of the same white supremacist idol more broadly worshipped as the majority religion of US society.

To be clear, the problem does not only or even primarily center upon the bare fact that the majority of Catholic theologians in this context are white, but rather upon the question of whether as a group they participate in a pattern of mostly unexamined cultural dominance, or whiteness. Perhaps what Massingale has observed about the church applies to its theologians and ethicists as well: "What makes the US Catholic Church a 'white racist institution,' then, is not the fact that the majority of its members are of European descent.... What makes it 'white' and 'racist' is the pervasive belief that European aesthetics, music, theology, and persons-and only these-are standard, normative, universal, and truly 'Catholic.'”26

To the extent that the majority of the Catholic theological academy fails to reckon adequately with its own whiteness, the quality of ethical reflection in that group will to that same extent be deficient. As Margaret Pfeil argues, "Insofar as the privileges conferred by the standpoint of whiteness escape critical scrutiny by those who are white, the social location of whiteness can be

${ }^{25}$ My use of the language of "complicity" to understand moral implication in a white supremacist system is borrowed from the work of Alex Mikulich, Laurie Cassidy, and Margaret Pfeil, The Scandal of White Complicity in US Hyper-Incarceration: A Nonviolent Spirituality of White Resistance (New York: Palgrave Macmillan, 2013).

${ }^{26}$ Bryan Massingale, Racial Justice and the Catholic Church (Maryknoll, NY: Orbis Books, 2010), 80. 
considered epistemologically compromised." ${ }^{27}$ Assuming it is true that the race privilege of whiteness corrupts moral epistemological capacities, it is reasonable to expect that, in general, a large group comprised predominantly of white people who live in a broader structural and ideological context of racial hierarchy, and who claim to be professional experts in moral analysis, would actually themselves be a grave moral danger. Thus, a radical inversion of the academic gaze requires nothing less than Catholic ethicists, and white Catholic ethicists in particular, asking the same self-critical question recently posed by Katie Grimes (who is herself redeploying a quotation from W. E. B. Du Bois): "How does it feel to be a problem?" 28

Catholic ethicists of color, who are familiar with the experience of being perceived as a problem, who write with comparatively greater moral epistemological acuity than whites about race and racism, and who are often taxed by doing a disproportionate share of the work of addressing these topics in the academy, are often preoccupied by a different question: "What must we do to survive in a world of white supremacy?" If Catholic ethicists of color do choose to participate in ritualized whiteness, it is usually a strategic choice done for the sake of survival in an institutional culture that offers few alternatives. Since white bodies have the central role in maintaining white supremacy, and because I am in no position to advise Catholic ethicists of color, I will focus on strategies for dismantling this performed identity among white Catholic ethicists.

As previously suggested, it would seem that one viable way for white Catholic ethicists to encounter our ideologically compromised bodily subjectivity as a radical problem is to infer from the narratives constructed by the movement the contours of the white supremacist "antitheology" operative underneath the surface of our explicitly elaborated theology and ethics, and to receive this intellectual revelation as a "call to conversion." After all, the reason why black women and gender-conforming persons reported feeling fatigued is that it is objectively exhausting and psychologically traumatizing to encounter persistent white supremacist and patriarchal opposition to the legitimacy of one's own very existence as a black body. The dehumanization narrative suggests a white supremacist denial that black bodies are created in the image of God by overemphasizing, on the one hand, black collectivity and

${ }^{27}$ Margaret Pfeil, "The Transformative Power of the Periphery: Can a White US Catholic Opt for the Poor?," in Interrupting White Privilege: Catholic Theologians Break the Silence, ed. Laurie Cassidy and Alex Mikulich (Maryknoll, NY: Orbis Books, 2007), 127-46, at 130.

${ }^{28}$ Du Bois, Souls of Black Folk, 2; and Katie Grimes, "Breaking the Body of Christ: The Sacraments of Initiation in a Habitat of White Supremacy," Political Theology 18, no. 1 (2017): 22-43, at 23. 
criminality, and on the other hand, white individuality and innocencealmost a Manichean, antitheological anthropology. The myth-debunking narrative suggests not only the general concealment of social sin as a plausible lie covertly embedded in social structures but also specific sinful beliefs: that the policing and criminal justice systems are benevolent, that good people need not fear arbitrary punishment within them, that racial differences are based in biological and/or cultural essences, that human worth and dignity must be earned through obedience to the imperatives of a political and economic status quo hostile to black flourishing. The delayed-liberation narrative suggests the myopia of a superficially liberal version of social "progress," in which King's "moral arc of the universe" will inevitably bend toward justice without any grassroots resistance from oppressed groups being needed. When we hold this white supremacist antitheology before our faces as a mirror, it has the capacity to "prick" our conscience.

There is good reason, however, to suspect that this approach will not work as a stand-alone strategy, inasmuch as whiteness, being the privileged mode of participation in the broader system of white supremacy and structural racism, has a "preconscious and nonrational character," making it "impervious to rational appeals and cognitive strategies." ${ }^{29}$ Indeed, whiteness is a "habitus," described sociologically by Eduardo Bonilla-Silva as "a racialized, uninterrupted socialization process that conditions and creates whites' racial taste, perceptions, feelings, and emotions and their views on racial matters." ${ }^{\circ}$ Sara Ahmed offers a complementary phenomenological description of white habitus as that "which orientates bodies in specific directions, affecting how they 'take up' space," as that which "trails behind" the actions of white bodies, shaping "what bodies can do." The upshot is that white bodies can shape and are able to be shaped by actions and institutional spaces in a pattern that is rarely perceptible to themselves and in a way that black and brown bodies can and do not; thus "white bodies are habitual." ${ }^{1}$ Given the habitual character of whiteness as it structures our embodied

29 Massingale, Racial Justice and the Catholic Church, 104-5.

3o Bonilla-Silva, Racism without Racists, 105, emphasis in the original. Alex Mikulich draws upon this concept of "white habitus" extensively in his constructive theological-ethical response to mass incarceration; see Mikulich, "White Complicity in US HyperIncarceration," in Mikulich, Cassidy, and Pfeil, The Scandal of White Complicity, 5986, at 76-81.

31 Sara Ahmed, “A Phenomenology of Whiteness," Feminist Theory 8, no. 2 (2007): 149-68, at 150, 156. Both Bonilla-Silva and Ahmed are drawing upon and extending Pierre Bourdieu's notion of "habitus" as a way of describing what white privilege does and how it operates in a racially hierarchical society; see Bourdieu, The Logic of Practice, trans. Richard Nice (Stanford, CA: Stanford University Press, 1990). 
agency, combined with the fact of the rational nonintelligibility of racism as moral evil, it is perhaps less than realistic to hope that the social body of professional Catholic ethicists are able to be "converted" away from white supremacy solely by means of an intellectual appeal.

Moreover, there are sociological and psychological reasons to be pessimistic about the success of such an approach. Political theologian and rhetorician Vincent Lloyd recently suggested that a system of social domination such as white supremacy typically conditions its primary beneficiaries to cooperate in making a partial response to critiques coming from its discontents, the ultimate "intention" being to maintain the status quo: "for when the privileged act in concert, whatever their goal, the result is to further privilege: social capital, like all capital, is fecund." ${ }^{2}$ Therefore, there is a serious danger embedded even in the attempts of "converted" or "well-intended" white liberals in the theological academy to renounce their privilege and organize against structural racism, in that their efforts may ultimately succeed in repositioning themselves as "the good white people." Alex Mikulich poses the question well: "How do white theologians and ethicists name their social location without re-inscribing White privilege and the systems of inequality it sustains?"33

As an alternative to a pure "conversion" approach, I suggest that all Catholic theologians and ethicists, including not only white bodies but also bodies of color, can encounter the challenge of the Black Lives Matter movement theologically by engaging intersectional opportunities for resistance, essentially recapitulating at the level of academic discourse the organic coalition-building process by which the movement built its own social body in the streets of Ferguson and elsewhere. Although intersectionality theory was originally elaborated in the interest of accurately understanding how multiple axes of oppression interlock in the social location of black women, ${ }^{34}$ it also provides an intellectual rationale for investigating latent capacities for resistance in the context of a heterogeneous group. Such an intersectional approach is already suggested by Copeland's observation that race, gender, and sexuality are “'co-constitutive' in empire.” 35 Recalling the

32 Lloyd, "For What Are Whites to Hope?," 178.

33 Alex Mikulich, "Mapping 'Whiteness': The Complexity of Racial Formation and the Subversive Moral Imagination of the "Motley Crowd," Journal of the Society of Christian Ethics 25, no. 1 (2005): 99-122, at 116.

34 See Kimberlé Crenshaw, "Demarginalizing the Intersection of Race and Class: A Black Feminist Critique of Antidiscrimination Doctrine, Feminist Theory, and Antiracist Politics," University of Chicago Legal Forum 140 (1989): 139-67; and Patricia Hill Collins, Black Feminist Thought: Knowledge, Consciousness, and the Politics of Empowerment, 2nd ed. (New York: Routledge, 2000), 8-12.

35 Copeland, Enfleshing Freedom, 66, 73. 
dangerous memory of the Jesus movement's own struggle with the interlocking systems of Roman imperial oppression, ${ }^{36}$ Copeland argues that bodies similarly endowed with freedom and dignity will be differently abused, disregarded, and erased by empire in accordance with the overlapping effects of its systems of oppression on the complex social locations occupied by those bodies. Accordingly, being attentive to shared insights and convergences grounded in particular experiences of oppression, even across the boundaries of irreducible difference, can constitute a practical basis for empathy, critical consciousness, solidarity, and resistance. ${ }^{37}$ Emilie Townes similarly observes that no historical or contemporary example of hegemonic social control has ever been absolute or complete; there are always "subversive spaces within the status quo" that present themselves as opportunities for articulating and enacting counternarratives. ${ }^{38}$

The use of an intersectional method as guide for restructuring theological ethics discourse away from whiteness does not necessarily imply that social analysis is fated to capitulate to an "oppression olympics," in which the recognition of the varieties of suffering becomes a competition-quite the opposite, in fact. Rather, if US Catholic ethicists take seriously the fact that they practice their profession in the context of an empire, then the fact that the wounds of oppression are differently, though analogously, inscribed on our own bodies means that we have rich opportunities for the kind of empathy that emboldens resistance, both in thought and in action. To be more specific, this work of intersectional resistance will invite white ethicists to cultivate two main "dissonances" (to use a musical metaphor) as they reckon with their whiteness: a critical consciousness that can anticipate ideological traps in natural law reasoning and a lack of naïve confidence in the sacramental system as a reliable locus of normative moral development in virtue.

\section{Black Lives Matter as Natural Law}

Regarding the first dissonance, Catholic ethics as a discipline is particularly susceptible to ideology because of its historical and contemporary commitment to natural law as a style and method of ethical reasoning. As is already well known, the uses and abuses of natural law have been laid bare by multiple critiques both modern and postmodern: it conflates descriptive and normative ethical claims; it presupposes a universal concept of practical reason that cannot accommodate real global and cross-cultural pluralism in

${ }^{36}$ See Copeland, Enfleshing Freedom, 58-62.

37 See Copeland, Enfleshing Freedom, 20-21, 99-101, 124-28.

${ }^{38}$ Emilie Townes, Womanist Ethics and the Cultural Production of Evil (New York: Palgrave Macmillan, 2006), 22. 
moral thought and practice; it presupposes a concept of "nature" that eludes a precise and consistent definition; it has historically privileged forms of knowledge that reflect the epistemological standpoints and political interests of those who occupy dominant social locations, to the detriment of socially subjugated groups; it has often, if not usually, been applied to particular issues in a deductive fashion; and it tends to promote, in the interest of maintaining an illusion of universality, a certain amount of historical amnesia about the fact that the content of morality develops. ${ }^{39}$

Yet the need for something like natural law persists. Political struggles against the reality of systemic oppression necessarily presuppose that subjugated peoples have the epistemological capacity to level moral indictment against their oppressors on the basis of a universal moral reference point, such as basic human dignity and freedom. For instance, Cristina Traina has argued that despite the antifeminist abuses of natural law, feminist ethical thought actually requires a carefully reconstructed and nuanced version of natural law epistemology, one grounded in a normative description of flourishing and in emancipatory practices, as the most viable intellectual basis for promoting and attaining feminist political goals. ${ }^{40}$ By extension, peoples subject to different axes of oppression would find analogous versions of natural law reasoning (again, carefully reconstructed) to be indispensable for their own liberation.

In this light, the unconditional ethical claim of Black Lives Matter about the intrinsic value of black life can be understood, from the standpoint of Catholic ethics, as a natural law claim. ${ }^{41}$ Although the movement does and

${ }^{39}$ For extended discussions of the critiques of natural law theory, as well as critical reconstructions in response to these critiques, see Jean Porter, "Does the Natural Law Provide a Universally Valid Morality?," in Intractable Disputes about the Natural Law: Alasdair MacIntyre and Critics, ed. Lawrence Cunningham (Notre Dame, IN: University of Notre Dame Press, 2009), 53-95; Porter, Nature as Reason: A Thomistic Theory of the Natural Law (Grand Rapids, MI: Eerdmans, 2005), 1-52; Martha Nussbaum, Creating Capabilities: The Human Development Approach (Cambridge, MA: Harvard University Press, 2011), 28-32, 129-32; Nussbaum, Women and Human Development: The Capabilities Approach (New York: Cambridge University Press, 2000), 252-54; Lisa Sowle Cahill, "Toward Global Ethics," Theological Studies 63, no. 2 (2002): 324-44; Lisa Sowle Cahill, Global Justice, Christology, and Christian Ethics (New York: Cambridge University Press, 2013), 248-84; and John T. Noonan Jr., A Church That Can and Cannot Change: The Development of Catholic Moral Teaching (Notre Dame, IN: University of Notre Dame Press, 2005).

${ }^{40}$ See Cristina Traina, Feminist Ethics and Natural Law: The End of the Anathemas (Washington, DC: Georgetown University Press, 1999).

${ }^{41}$ Here I follow Vincent Lloyd's recent work, in which he provides a contemporary retrieval of the use of natural law rhetoric and argumentation in historical struggles for black liberation; see Lloyd, Black Natural Law (New York: Oxford University Press, 2016). 
must employ critical race theory and postcolonial critique in order to deconstruct whiteness and expose mass complicity in white supremacy, our method of doing ethics is unapologetically foundationalist, in that we also envision a different world based upon an affirmation of the value of black life and propose a design for institutional structures capable of protecting this value. The imperative to protect the contingent flourishing of black life from injury and death serves as the telos by reference to which different tactics of resistance pursued by the movement are intelligible as prudential action. In other words, symbolic shutdowns of highways are undertaken not because cultural disruption is a good in itself, but rather because black life is under severe threat due to structural injustices manifest in the everyday and mundane, such as targeted traffic stops of black and brown bodies that turn deadly. Translated into the language of Catholic social ethics, white bodies have hijacked the institutional structure of society for private benefit, and their complicity in this injustice includes preventing black and brown bodies from attaining flourishing and equitable participation in the common good at the most basic level of biological survival, both physiological and psychological. Thus, the movement makes an appeal to a higher law of human dignity, respect, and rights because it is an indispensable intellectual and rhetorical tool for constructing an effective moral argument against the legitimacy of a racially hierarchical society.

However, the ethical claim of the intrinsic value of black life simply cannot be reliably known and understood as a natural law claim by white scholars operating in a purely conceptual mode, in consideration of the formative influence of whiteness upon their patterns of thought. That a credible response to racial injustices would necessarily include radical redistribution of power and resources, restructuring of society, and cultural transformation is unlikely to seem "reasonable" or "natural" to white bodies deeply invested in white supremacy. Rather, this truth can be discovered only in the context of participation in organizations and symbolic practices that already affirm the value of black life, by taking advantage of the opportunities for cognitive dissonance in the intersectional relationships and identities already present within the Catholic theological academy. Thus, the Black Lives Matter movement challenges Catholic ethicists to acknowledge the epistemic privilege of black natural law and to conceive of and practice natural law as a style of reasoning that is necessarily radically situated in a praxis of resistance and solidarity. ${ }^{42}$

42 See Lloyd, Black Natural Law, ix. 


\section{The Virtuous Unperforming of Vicious Whiteness}

The second dissonance mentioned above, that of avoiding undue optimism about the sacramental cultivation of antiracism virtues, is surely a major point of debate relevant to this discussion. Any response to this question would bear upon the influence of performed whiteness not only among Catholic theological scholars working in the US context but also among US Catholics more broadly. "Virtue" is the name Catholic ethicists generally give to the normative dispositions necessary for exercising human agency reliably in actions and social policies that will promote both the common good of political society and the flourishing of all individual members of that society. Solidarity, for example, is the primary virtue necessary for disposing individuals, groups, and structures to adopt a praxis capable of protecting and promoting human rights. ${ }^{43}$ Conversely, vice can be understood as a disposition of failure-that which disposes not only individuals but also the social groups and systems in which these individuals participate to elevate the habitual pursuit of an instrumental good or private interest as an ultimate end, thereby failing to regard the flourishing of all as society's goal. ${ }^{44}$ It is fairly clear that fruitful analogies are possible between this Thomistic understanding of vice as habit and the discussions of white habitus found in Bonilla-Silva, Ahmed, and Copeland, as suggested by Grimes' recent work. 45 The live questions are the following: How do we understand the cultivation of this vice of whiteness from the perspective of performativity and through a ritual participation lens? What are the best ways to name, understand, and ultimately reverse this socialization process? And, most provocatively, is the Catholic sacramental system of any use in this task, or does it impede the work of dismantling white supremacy?

Although articulating such answers could well occupy several investigations, a beginning of a response can be found in querying the extent to which Catholic ritual participation, as that which performs the identity of the Catholic social body, is a reliable basis for resisting the contrary habituation by which the vice of whiteness "orientates bodies in specific directions, affecting how they 'take up' space," and determining what they can do." 46 Massingale and Copeland advance the possibility that participation in sacraments such as baptism and Eucharist can empower a praxis of solidarity and

${ }^{43}$ See Meghan Clark, The Vision of Catholic Social Thought: The Virtue of Solidarity and the Praxis of Human Rights (Minneapolis: Fortress Press, 2014).

${ }^{44}$ See Daniel Daly, "Structures of Virtue and Vice," New Blackfriars 92 (2011): 341-57.

45 See Grimes, "Breaking the Body of Christ"; and Mikulich, Cassidy, and Pfeil, The Scandal of White Complicity.

${ }^{46}$ Ahmed, "A Phenomenology of Whiteness," 150. 
resistance, provided that the social body encounters the symbols with fidelity to the "dangerous memory" of the original practice and intentionality of the Jesus movement (radical solidarity with and among the oppressed), and that they accurately connect this symbolic mediation with contemporary oppressed bodies struggling for liberation. ${ }^{47}$ Grimes, however, expresses a note of caution about such optimistic proposals on the grounds that the social body of the Catholic Church occupies racially segregated space in the US context, such that its individual white bodies will be unlikely through sacramental participation to "metabolize," so to speak, the symbol as a source of resistance to the status quo. ${ }^{48}$ The historical record indicates that "rather than re-conditioning the racialized white Catholic body, embodied Catholic practices of incorporation have tended to, at best, capitulate to, or, at worst, amplify and affirm the habituating power of white supremacy." 49

Therefore, it would seem that whatever symbolic power or cultural resonance the sacraments may have for challenging racism at a conceptual or practical level, it is by no means clear that participation in them can function or ever has functioned historically as a way for white Catholic bodies to "unperform" their whiteness habituation or to "reperform" themselves into a new, transgressive social body characterized by normative dispositions of racial justice, which is to say, antiracism virtues. Such virtues might include a mercy that decenters dominant voices and prioritizes subjugated voices, a solidarity that prefers the conflictual pursuit of justice for victims over the maintenance of an ordered social peace, and a sense of equity that understands the goals and procedures of political society not in terms of simple equality but in light of the historical and contemporary denial of justice to subjugated and colonized peoples. ${ }^{50}$

If the matter of cultivating these antiracism virtues were in fact as simple as making sure that those participating in sacraments were

47 See Massingale, Racial Justice and the Catholic Church, 125; and Copeland, Enfleshing Freedom, 108.

${ }^{48}$ Grimes, "Breaking the Body of Christ," 38.

49 Ibid., 39; Grimes provides an overview of the historical uses of baptism and Eucharist in support of white supremacy at 24-34.

${ }^{50}$ For mercy as a decentering, see Jon Sobrino, The Principle of Mercy: Taking the Crucified People from the Cross (Maryknoll, NY: Orbis Books, 1994), 15-26. For conflictual solidarity, see Bryan Massingale, "Vox Victimarum Vox Dei: Malcolm X as Neglected 'Classic' for Catholic Theological Reflection,” CTSA Proceedings 65 (2010): 63-88, at 81-84. Maureen O'Connell proposes vigilance, counter-framing, and sitting-with-it as three "cardinal virtues of antiracist racists" in "After White Supremacy? The Viability of Virtue Ethics for Racial Justice," Journal of Moral Theology 3, no. 1 (2014): 83-104, at 100-104. 
consciously experiencing them as a ritual anamnesis of dangerous memory, ${ }^{51}$ then we might reasonably expect Catholics not only to exemplify these virtues more reliably but also to demonstrate more interest and investment in movements for racial justice than adherents of other religious and cultural systems that are comparatively less ritually and symbolically dense. As it happens, the visible religious support for the Black Lives Matter movement at present is overwhelmingly comprised of a coalition of secular groups, Black Protestants, so-called mainline White Protestants, Jews, and Muslims. Although this evidence is admittedly anecdotal, I was in fact surprised and ashamed during my research in the St. Louis area that so few Catholics were present at protests, despite the large Catholic population in the region and a strong stated commitment to social justice on the part of their official leadership. The few Catholics who were present were themselves often enough "marginal" in some way within their own tradition, either because of having well-developed feminist social hermeneutics, being queer or having a queer member of their family, being a black or brown body themselves, being a member of a transracial family, being in an interracial relationship, or some intersection of two or more of the above cases.

There is some hope for Catholic sacramental participation as an interruption of whiteness-habituated bodies and a route to reperforming a new social body, but only to the extent that the white bodies aiming to unperform their whiteness are already also being interrupted by participation in genuinely intersectional political spaces where the suffering of, liberation by, and solidarity among black and brown, female, and transgender bodies are the central concerns. Spaces characterized by these concerns are few and difficult to sustain among Catholic ethicists, at least in part because of the sheer numerical dominance of white bodies and because we only meet as a group at professional conferences a few times per year. Therefore, a great deal of the development of antiracism virtues among Catholic ethicists depends upon the kinds of political spaces these bodies occupy in addition to their professional work and how skillfully they engage differences of race, gender, class, and sexuality in those spaces. Absent such opportunities, it is unlikely that Catholic ethicists or Catholics more generally will be able to identify the dangerous memory of Christ's unjust execution by the Roman state with contemporary black and brown bodies being killed unjustly by the American state, as Massingale's and Copeland's arguments suggest would be necessary for virtuous development in and through sacramental participation.

${ }^{51}$ See Bruce Morrill, Anamnesis as Dangerous Memory: Political and Liturgical Theology in Dialogue (Collegeville, MN: Liturgical Press, 2000). 


\section{Conclusion}

As an academic discipline considered in the US context, Catholic ethics is invested in white supremacy not only because it is a majority-white profession whose members benefit from structural racism but also because its members habitually perform whiteness. Neither they nor their discipline is special in this regard because the same is true of virtually every other major institution in the United States, both historically and at the present time. This is precisely the major moral critique of the Black Lives Matter movement: a nation professing adherence to cultural values such as freedom, justice, and equality before the law is in fact complicit in an extensive and complex system of white dominance that devalues black life as an object of particular scorn and disregard.

Qualitative data collected during field research among members of this movement indicate that our use of direct action to level this moral critique functions symbolically and performatively, in that it constructs a new collective identity comprised of four interlocking narratives of fatigue, dehumanization, myth debunking, and delayed liberation. This narrative-based collective identity is a necessary condition for this emerging social body to exercise its collective agency, which we do primarily in the mode of indirect cultural and symbolic subversion and secondarily in the mode of direct structural participation, for the ultimate purpose of dismantling white supremacy as a clear and present threat to the flourishing of black and brown bodies.

Scholars of Catholic ethics who wish to respond to Black Lives Matter must consider that internalizing the intrinsic value of black life as a natural law claim demanding subsequent radical self-critique and intragroup critique should not merely prompt a desire for conversion, which is necessary but not sufficient. Full internalization of the critique also implies the need for an intersectional approach by which to unperform whiteness from the habituation of their Catholic social body and to reperform antiracism virtues of mercy, solidarity, and equity. ${ }^{52}$

${ }^{52}$ This article was developed from a paper presented at the College Theology Society in June 2016. For their critical comments and general support throughout the completion of this project, I would like to thank Jessica Wrobleski, Nancy Rourke, Craig Ford, Gerald Beyer, Kevin Ahern, Tobias Winright, Julie Rubio, Katie Grimes, Meghan Clark, Jodi O'Brien, Rachel Luft, Stefan Bradley, and James Keenan. For the grant that funded my research, without which this project would have been impossible, I would like to thank Catherine Punsalan-Manlimos and the Institute for Catholic Thought and Culture at Seattle University. For their fine work in transcribing the interviews, I would like to thank Letta Page and Hope Uggen. As a final note, it is difficult for me to express my immense gratitude to the 23 members of the movement who consented to participate in the research, without whose trust, candor, voices, and social witness I would not have been able to write this article. 